\title{
Association between platelet-rich fibrin and collagen matrix for root coverage: Case Series.
}

\author{
Mauricio Andres Tinajero-Aroni ${ }^{1}$, Suzane Cristina Pigossi ${ }^{2}$, Guilherme José Pimentel-Oliveira ${ }^{3}$, \\ Elton Carlos Pichotano ${ }^{4}$, Rosemary Adriana Chierici-Marcantonio ${ }^{4}$.
}

\begin{abstract}
1. Department of Periodontics and Implant Dentistry, San Francisco de Quito University (USFQ), Quito-Ecuador. 2. School of Dentistry, Alfenas Federal University (Unifal-MG), Alfenas, Minas Gerais, Brazil. 3. Department of Periodontology, School of Dentistry, Uberlandia Federal University (UFU), Uberlandia, Minas Gerais, Brazil.

4. Department of Diagnosis and Surgery, School of Dentistry at Araraquara, UNESP-São Paulo State University, SP, Brazil.
\end{abstract}

\author{
* Correspondence Author: Profa. Rosemary \\ Adriana-Marcantonio | Department of Diagnosis \\ and Surgery, Universidade Estadual Paulista - \\ UNESP, Araraquara-SP, Brazil | Address: Humaitá, \\ 1680, Araraquara, SP, Brazil -14801-903 | E-Mail: \\ adriana@foar.unesp.br. \\ Work received on 02/04/2020. \\ Revised work: 25/06/2020
}

Approved for publication on 17/07/2020

\section{ABSTRACT}

The aim of this case series was to evaluate the effectiveness of the collagen matrix (CM) associated with platelet-rich fibrin (PRF) in the treatment of gingival recession (GR). Six non-smoker patients that presented at least one site with single GR in the maxilla were included. Four GR were treated with conventional coronally advanced flap and six GR were treated with a modified coronally advanced tunnel technique. In both techniques, the PRF was immobilized above the CM. A reduction in the GR depth $(2.00 \mathrm{~mm}(1.50-3.50)$ to $0.00(0.00-0.00))$ and pocket probing depth $(1.25 \mathrm{~mm}$ $(1.00-2.00)$ to $1.00 \mathrm{~mm}(1.00-1.62))$ resulting in complete root coverage in all GR after 1 month. However, a displacement of the marginal gingival of $0.50(0.00-1.00)$ associated with a gingival thickness reduction (1.35 (0.90-1.82)) was observed after 12 months. The association of the CM and PRF was effective in the GR coverage. KEY WORDS:

Collagen; Esthetics, Dental; Gingival recession; Platelet-rich fibrin; Maxilla

Int. J. Inter. Dent Vol. 14(1); 48-51, 2021.

\section{INTRODUCTION}

Many periodontal plastic surgery techniques and flap designs have been proposed to obtain a highly predictable and long-term root coverage by augmenting gingival tissue dimensions. Among the available techniques, the conventional coronally advanced flap (CCAF) associated with a connective tissue graft (CTG) is considered a gold standard technique with a significantly higher percentage of root coverage and keratinized tissue gain. However, CTG harvesting is associated with increased patient morbidity, prolonged surgical time and postoperative complications (bleeding, numbness and sensibility changes in the donor area) ${ }^{(1)}$.

Mucograft ${ }^{\circledR}$ is a resorbing porcine matrix composed of a bilayer structure of collagen type I and type III, which acts as a substitute in cases of loss of the connective tissue structure around teeth and implants. This collagen matrix (CM) guarantees unlimited availability, surgical time decrease and fewer postoperative complications due to the lack of a donor site ${ }^{(2)}$. A recent systematic review and meta-analysis showed that no significant differences were detected in the percentage of mean root coverage (MRC) and recession reduction (RR) between CM and CTG in single or multiple recession. Nevertheless, a higher percentage of complete root coverage (CRC) and greater keratinized tissue (KT) gain could be observed in the CTG group at multiple recessions ${ }^{(2)}$.

The platelet-rich fibrin (PRF) is an autologous fibrin matrix containing $50 \%$ of the leukocytes from the original blood volume. This threedimensional fibrin matrix acts as a support for the cells during the regenerative process ${ }^{(3)}$. Moreover, in vitro studies have demonstrated a slow release of several growth factors including transforming growth factor $\beta 1$, platelet-derived growth factor and vascular endothelial growth factor during the first 7 days in sterile medium ${ }^{(3)}$. In general, clinical studies have shown that CCAF alone or in combination with the PRF membrane are highly predictable procedures for the treatment of Miller Class I and II gingival recessions. However, the use of PRF membrane resulted in enhanced soft-tissue healing in terms of colour and tissue texture(4) and KT gain in comparison to CCAF alone after $6^{(5)}$ and 12 months ${ }^{(4)}$

Therefore, we proposed the use of PRF as a combination material, based on its potential to enhance fibroblast activity and angiogenesis stimulation, to improve the $\mathrm{CM}$ clinical results. Therefore, this case series aimed to present the effect of the $\mathrm{CM}$ associated with PRF in the treatment of gingival recessions concerning root coverage and KT gain.

\section{CASE REPORTS}

\section{Patients Informations}

Six non-smokers, systemically healthy patients (4 females, 2 males, aged 20 to 42 years) who had at least one site with single gingival recession (recession type 1 (RT1) class or Miller Class I and II) in the maxilla were included in this case series (Figure 1 and 2). To be included in this case series the patients also required to present less than $20 \%$ of plaque index; the gingival recession must be presented in canine or premolar tooth in the ideal position (without individual malpositions according to Lischer Classification ${ }^{(6)}$ ) and a negative history of previous surgical procedures or periodontal disease. The clinical measurements were made at the mid-buccal point of the involved teeth at baseline (before surgery), 1, 3, 6 and 12 months by the same investigator (M.A.T.A) using the same type of periodontal probe (UNC 15, Hu-Friedy, Chicago, IL, USA).

The following parameters were assessed: (1) gingival recession depth (GRD in $\mathrm{mm}$ ) measured as the distance from the CEJ to the gingival margin; (2) pocket probing depth (PPD in $\mathrm{mm}$ ), which was analyzed at the distobuccal, mid-buccal and mesiobuccal aspects of surgical sites, and was considered the distance from the gingival margin to the apical portion of the periodontal sulcus; (3) keratinized tissue width (KTW) (in $\mathrm{mm}$ ), measured as the distance from the mucogingival junction (MGJ) to the gingival margin; (4) gingival thickness (GT mm) measured $3 \mathrm{~mm}$ apically from the free gingival margin at the mid-buccal aspect of the tooth using a dental endodontic hand file (K File Kerr 30mm \#10).

\section{Therapeutic Intervention}

Before the surgical procedure, the PRF membranes' preparation, according to the technique described by Choukroun et al. (7), was initiated. During the PRF centrifugation (10 minutes at 3000 RPM), local anesthesia was induced using a $4 \%$ articaine solution with epinephrine 1:100.000 (Nova DFL). Two different types of flap were used according to the GRD: conventional coronally advanced flap (CCAF) in four larger and wider gingival recessions (GDR: 4.00 (3.00-5.37)) (Figure 3A and $3 \mathrm{~B}$ ) and modified coronally advanced tunnel (MCAT) in six small and shallow gingival recessions (GDR 1.75 (1.50-2.00)) (Figure 4A and 4B).

For the CCAF technique, a trapezoidal full mucoperiosteal flap was raised to the MGJ and a partial thickness flap was made apically to the mucogingival junction (MGJ) allowing a tension-free coronal flap position (Figure 3C-G). The adjacent papillae were de-epithelized 


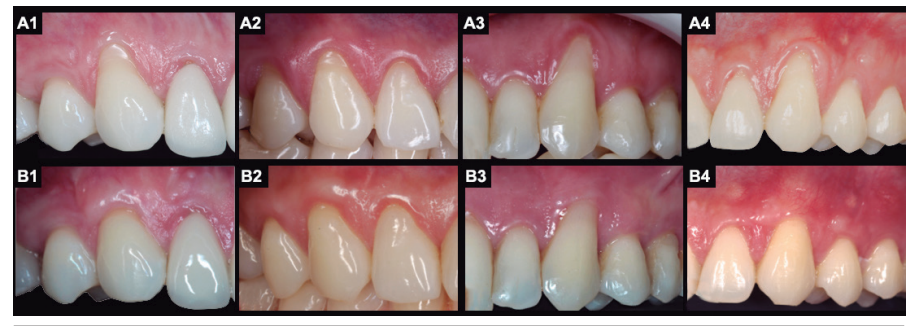

Figure 1: Pretreatment (A) and after 12 months (B) view of each case using conventional coronally advanced flap technique plus collagen matrix and platelet rich fibrin included in this case series; A1/B1: right upper canine teeth; A2/B2: right upper canine teeth; A3/B3: left upper canine teeth and A4/B4: left upper canine teeth.

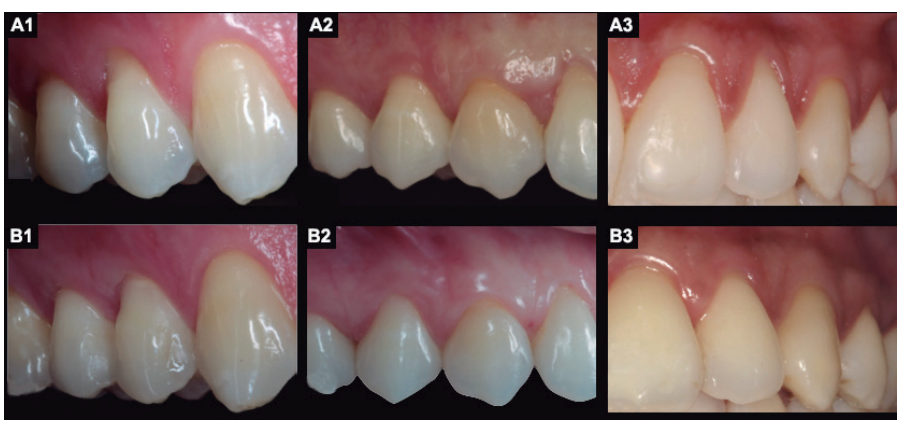

Figure 2: Pretreatment $(A)$ and after 12 months $(B)$ view of three of six cases included in this case series using the modified coronally advanced tunnel technique plus collagen matrix and platelet rich fibrin; A1/B1: right upper first premolar teeth; A2/B2: right upper canine teeth and A3/B3: left upper lateral incisor teeth.

(Figure 3F), and the root surface debridement was made using Gracey curettes (Hu-Friedy, RJ, Brazil). For the MCAT, intrasulcular incisions were performed and mucoperiosteal flaps were raised using sharp tunnel elevators preserving the papillae (Quinelato, Brazil) (Figure $4 \mathrm{D}$ and $4 \mathrm{E})$. The flap was extended beyond the MGJ and under each papilla allowing a tension-free flap mobilization in the coronal direction (Figure 4F).

After the flap preparation, the $\mathrm{CM}$ (Mucograft ${ }^{\circledR}$ collagen matrix, Switzerland) was cut and trimmed to the exact size of the defect, such that $\geq 1 \mathrm{~mm}$ of the surrounding tissue was covered (Figure $3 \mathrm{H}$ and $4 G)$. For the CCAF technique, the CM was immobilized in the surgical site with a subperiosteal suture $\left(\right.$ Marlin $^{\circledR}$ violet, absorbable, DSM 11, 6-0) (Figure 3I). The PRF membrane was also immobilized above to the CM using the same suture (Figure $3 \mathrm{~J}$ and $3 \mathrm{~K}$ ). For the MCAT technique, both materials (Figure $4 \mathrm{H}$ ) were sutured together (Figure $4 \mathrm{I}$ and $4 \mathrm{~J}$ ) and inserted into the tunnel (Figure 4K). A double-loop sling suture (Resorba ${ }^{\circledR}$ Sutures Resolon ${ }^{\mathrm{TM}}$, blue, USP 6/0) was made in the flap interdental region to positioned at or coronal to the cementoenamel junction (Figure $3 \mathrm{~L}$ and $4 \mathrm{~L}$ ). Only for the CCAF technique were additional interrupted sutures made in the release incision (Figure $3 \mathrm{~L}$ ). After 15 days, the post-surgery course was uneventful and the sutures were removed. The comparison between the baseline and final clinical appearance of three cases is shown in Figures 1 and 2 .

\section{Follow-up and Outcomes}

A total of 10 gingival recessions were treated in this case series and included in the statistical analysis (tooth-level analysis). Of these, four gingival recessions were treated with CCAF and six gingival recession with the MCAT technique. The GraphPad Prism 6 software (San Diego, CA, USA) was used. The Friedman test complemented by the Dunn test was used to evaluate clinical parameters longitudinally. Comparison between CCAF and MCAT techniques was made using Mann-Whitney Test. Differences were considered statistically significant when the $\mathrm{p}$-value was $<0.05$.

The median and 25th and 75th percentiles of periodontal clinical parameters at baseline, 1, 3, 6 and 12 months were showed in Table 1. The association between the PRF and $\mathrm{CM}$ promoted a reduction in the GRD $(2.00 \mathrm{~mm}(1.50-3.50)$ to $0.00(0.00-0.00))$ and PPD $(1.25$ $\mathrm{mm}(1.00-2.00)$ to $1.00 \mathrm{~mm}(1.00-1.62))$ resulting in complete root coverage in all gingival recessions after 1 month (Table 1). Moreover,

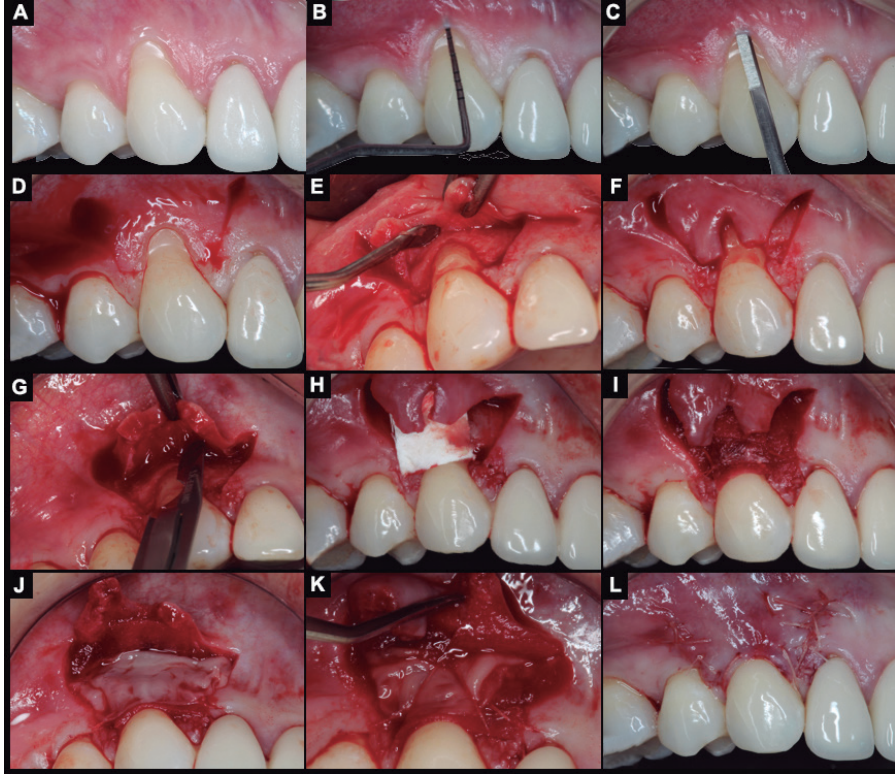

Figure 3: Representative case illustrating the root coverage procedure using conventional coronally advanced flap technique plus collagen matrix $(\mathrm{CM})$ and platelet rich fibrin (PRF). A: Pretreatment view of right upper canine teeth; B: Measurement of the pocket probing depth using a periodontal probe; $\mathrm{C}$ : Intrasulcular incision at the buccal aspect of the tooth; D: Two horizontal incisions performed at the adjacent papillae, at the level of the cement-enamel junction (CEJ), continued by two vertical incisions beyond the mucogingival junction; E, F and G: Trapezoidal full mucoperiosteal flap; $\mathrm{H}$ : CM cut and trimmed to the exact size of the defect; I: CM sutured in the surgical site; J: PRF positioned above the CM; K: PRF sutured in the surgical site; L: Final aspect of the flap suture.

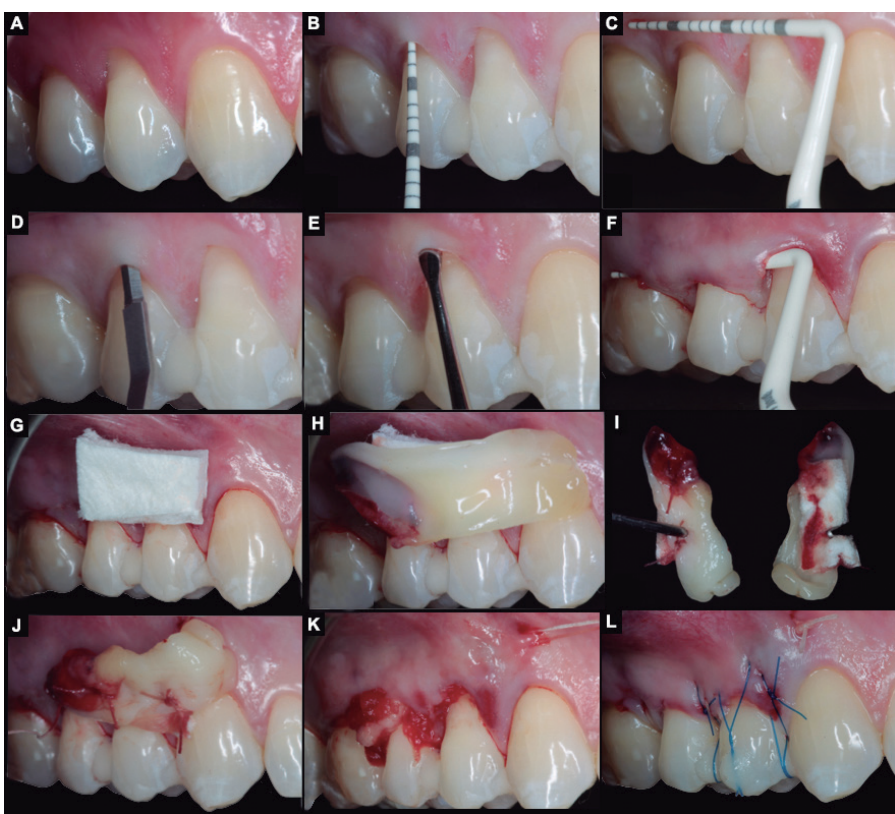

Figure 4: Representative case illustrating the root coverage procedure using the modified coronally advanced tunnel technique plus collagen matrix $(\mathrm{CM})$ and platelet rich fibrin (PRF). A: Pretreatment view of right upper premolar teeth; B: Measurement of the pocket probing depth using a periodontal probe; C: Mucogingival junction localization using a periodontal probe; D: Intrasulcular incisions with a microblade; E: Mucoperiosteal flaps using sharp tunnel elevators; F: Tension-free flap mobilization test using a periodontal probe; G: CM cut and trimmed to the exact size of the defect; $\mathrm{H}$ : PRF positioned above the $\mathrm{CM}$; I and J: PRF and CM sutured together; $\mathrm{K}$ : Both materials inserted in the tunnel; L: Final aspect of the flap suture. 
an increase in KTW $(1.25 \mathrm{~mm}(1.00-2.00)$ to $1.75(1.37-2.62))$ and GT $(1.00 \mathrm{~mm}(0.50-1.50)$ to $1.70(1.27-2.32))$ were also observed after 1 month (Table 1). However, apical displacement of the marginal gingival of $0.50(0.00-1.00)$ associated with a GT reduction (1.35 (0.90-1.82)) was observed after 12 months. The KTW gain obtained with the surgical procedure was maintained after 12 months (1.75 (1.37-2.25) (Table 1). The median and 25th and 75th percentiles of periodontal clinical parameters in the CCAF and MCAT techniques groups at baseline, 1, 3, 6 and 12 months were shown in Table 2. Comparing CCAF and MCAT techniques groups, no difference was observed in the GRD, PPD and GT in all analyzed periods (Table 2). A higher increase in the KTW was observed in the CCAF group in comparison to the MCAT technique in all analyzed periods (Table 2).

\section{DISCUSSION AND CONCLUSION}

Clinical studies have shown that the use of the CTG ensures superior clinical outcomes in comparison to the PRF and CM alone in gingival recessions treatment $(8,9)$. Based on that, the main aim of this case series was evaluated the association between CM and PRF in the treatment of gingival recessions. To our knowledge, no clinical study has yet been published evaluating the gingival recession coverage using both PRF and CM. The results of this study indicated a reduction in the GRD associated with KTW and GT increase after 12 months of follow-up. However, the number of participants included in this case series is insufficient (power analysis below $80 \%$ ) and it is necessary to have 12 patients per group to obtain an adequate sample size for this study ${ }^{(10)}$. Intra or inter-individual variations including the tooth kind and surgical technique can also interfere in the clinical results, however, no intra and inter-individual variability analysis between the individuals was possible due to the small number of participants included in this case series. Therefore, randomized clinical trials including a control group, flap design standardization and a larger number of patients should be performed to confirm these results.

Although a complete root coverage was obtained in all cases included in this case series after 1 month, apical displacement of the marginal gingival was observed after 12 months (GRD: 0.50 (0.001.00)). Similar results have been shown in controlled clinical studies comparing the treatment of Miller Class I and II single recessions with CCAF alone or in conjunction with $\mathrm{CM}^{(11,12)}$. Stefanini et al. $(2016)^{(11)}$ obtained a GRD of $0.83 \pm 0.99$ for $\mathrm{CM}$ alone (baseline $3.46 \pm 0.90$ ) in comparison to $0.93 \pm 1.10$ for CCAF alone (baseline $3.34 \pm 1.00$ ). Moreira et al. $(2016)^{(12)}$ also reported a GRD of $0.75 \mathrm{~mm} \pm 0.76$ for $\mathrm{CM}$ (baseline
$3.16 \pm 0.65$ ) and $0.89 \pm 0.52$ for CCAF alone (baseline $3.14 \pm 0.51$ ) after 6 months. On the other hand, better clinical results were observed by Cardaropoli et al. (2012)(13) with a smaller GRD of $0.23 \mathrm{~mm} \pm 0.47$ for CM (baseline $3.09 \pm 0.63$ ) and $0.09 \mathrm{~mm} \pm 0.20$ for CTG (baseline $3.05 \pm 0.65$ ) after 12 months. Therefore, in comparison to these clinical studies, the association between CM and PRF evaluated in this case series seems not to have shown superior root coverage in comparison to CM or CTG alone.

In this case series, the minimal KTW gain obtained with the surgical procedure was maintained after 12 months $(1.25 \mathrm{~mm}(1.00-2.00)$ to $1.75 \mathrm{~mm}(1.37-2.25))$. Likewise, Moreira et al. (2016)(12) showed a KTW gain of $0.20 \mathrm{~mm}$ after 6 months with CM alone. However, higher KTW gain of $1.23 \mathrm{~mm}$ and $1.05 \mathrm{~mm}$ was observed using CCAF+CM by Cardarapoli et al. (2012)(13) and Stefanini et al. (2016)(11) after 12 months, respectively. For the GT parameter, a statistically significant reduction in the GT gain was observed between 1 and 12 months, with a minimum GT gain obtained after 12 months $(1.00 \mathrm{~mm}(0.50-1.50$ to $1.35(0.90$ 1.82)). Minimal GT gain was also shown by Stefanini et al. (2016) (11) $(0.52 \mathrm{~mm})$ after 12 months and by Moreira et al. $(2016)^{(12)}(0.40 \mathrm{~mm})$ after 6 months. However, superior results were reported by Cardarapoli et al. (2012)(13) that obtained a gain of $1.00 \mathrm{~mm}$ in GT for CM and 1.23 $\mathrm{mm}$ for CTG after 12 months. Consequently, the KTW and GT results obtained in this case series also suggested that the PRF membrane did not increase CM clinical potential. This fact can be associated with the relatively rapid degradation of the PRF membrane, with the subsequent reduction in molecule release ${ }^{(14)}$, which could negatively interfere in the PRF potential to improve the soft-tissue healing in the long term.

For the small and shallow gingival recession, the MCAT was proposed which avoids vertical releasing incisions and does not incise the papillae, which in turn may improve vascularization of the area. This technique ensures a premature esthetic result and satisfactory healing, however, should be avoided in large recesses to avoid excessive graft exposure ${ }^{(15)}$. A significantly higher increase in the KTW was observed in the CCAF group in comparison to the MCAT technique in all analyzed periods. This can be attributed to the natural tendency of the MGJ to regain its original, genetically determined position once the CCAF technique promotes a higher coronal repositioning of the MGJ due to the vertical releasing incisions.

Within the limits of this case series, it is concluded that the association between the CM and PRF was effective for the treatment of Miller Class I and II gingival recession.

Table 1: Median and $25^{\text {th }}$ and $75^{\text {th }}$ percentiles of periodontal clinical parameters at baseline, $1,3,6$ and 12 months.

\begin{tabular}{l|l|l|l|l|l}
\hline \multicolumn{1}{c|}{ Parameter/Period } & \multicolumn{1}{c|}{ Baseline } & \multicolumn{1}{c|}{$\mathbf{1}$ month } & \multicolumn{1}{c|}{$\mathbf{3}$ months } & \multicolumn{1}{c}{$\mathbf{6}$ months } & \multicolumn{1}{c}{$\mathbf{1 2}$ months } \\
\hline $\begin{array}{l}\text { Gingival Recession } \\
\text { Depth }\end{array}$ & $2.00(1.50-3.50)^{\mathrm{a}}$ & $0.00(0.00-0.00)^{\mathrm{b}}$ & $0.50(0.00-0.50)^{\mathrm{b}}$ & $0.50(0.00-1.00)^{\mathrm{b}}$ & $0.50(0.00-1.00)^{\mathrm{b}}$ \\
\hline Pocket probing depth & $1.25(1.00-2.00)$ & $1.00(1.00-1.62)$ & $1.25(1.00-1.62)$ & $1.25(1.00-1.62)$ & $1.25(1.00-1.62)$ \\
\hline $\begin{array}{l}\text { Keratinized Tissue } \\
\text { Width }\end{array}$ & $1.25(1.00-2.00)^{\mathrm{b}}$ & $1.75(1.37-2.62)^{\mathrm{a}}$ & $1.75(1.37-2.25)^{\mathrm{a}, \mathrm{b}}$ & $1.75(1.37-2.25)^{\mathrm{a}, \mathrm{b}}$ & $1.75(1.37-2.25)^{\mathrm{a}, \mathrm{b}}$ \\
\hline Gingival thickness & $1.00(0.50-1.50)^{\mathrm{b}, \mathrm{c}}$ & $1.70(1.27-2.32)^{\mathrm{a}}$ & $1.45(0.95-2.00)^{\mathrm{a}, \mathrm{b}}$ & $1.35(0.90-1.82)^{\mathrm{b}}$ & $1.35(0.90-1.82)^{\mathrm{b}}$ \\
\hline
\end{tabular}

$a, b, c$ : Different letters represent statistically significant differences between each follow-up period $(p<0.05-$ Freidman and Dunn Test)

Table 2: Median and $25^{\text {th }}$ and $75^{\text {th }}$ percentiles of periodontal clinical parameters in both technique groups at baseline, $1,3,6$ and 12 months.

\begin{tabular}{|c|c|c|c|c|c|c|}
\hline \multicolumn{2}{|c|}{ Parameter/Period } & Baseline & 1 month & 3 months & 6 months & 12 months \\
\hline $\begin{array}{l}\text { Gingival } \\
\text { Recession } \\
\text { Depth }\end{array}$ & $\begin{array}{l}\text { MCAT } \\
\text { CCAF }\end{array}$ & $\begin{array}{l}1.75(1.50-2.00)^{\mathrm{b}^{* *}} \\
4.00(3.00-5.37)^{\mathrm{b}^{* *}}\end{array}$ & $\begin{array}{l}0.00(0.00-0.00)^{a} \\
0.00(0.00-0.75)^{a, b}\end{array}$ & $\begin{array}{l}0.50(0.37-0.50)^{a, b} \\
0.00(0.00-1.50)^{a, b}\end{array}$ & $\begin{array}{l}0.50(0.37-0.50)^{a, b} \\
0.00(0.00-1.50)^{a, b}\end{array}$ & $\begin{array}{l}0.50(0.37-0.50)^{a, b} \\
0.00(0.00-1.50)^{a, b}\end{array}$ \\
\hline $\begin{array}{l}\text { Pocket probing } \\
\text { depth }\end{array}$ & $\begin{array}{l}\text { MCAT } \\
\text { CCAF }\end{array}$ & $\begin{array}{l}1.00(1.00-1.00) \\
1.12(1.00-1.50)\end{array}$ & $\begin{array}{l}1.00(1.00-1.00) \\
1.00(1.00-1.25)\end{array}$ & $\begin{array}{l}1.00(1.00-1.50) \\
1.00(1.00-1.00)\end{array}$ & $\begin{array}{l}1.00(1.00-1.50) \\
1.00(1.00-1.00)\end{array}$ & $\begin{array}{l}1.00(1.00-1.50) \\
1.00(1.00-1.00)\end{array}$ \\
\hline $\begin{array}{l}\text { Keratinized } \\
\text { Tissue Width }\end{array}$ & $\begin{array}{l}\text { MCAT } \\
\text { CCAF }\end{array}$ & $\begin{array}{l}1.00(1.00-1.62) \\
1.75(1.12-2.75)^{\mathrm{b}}\end{array}$ & $\begin{array}{l}1.50(1.00-1.62)^{* *} \\
2.75(2.12-3.60)^{\mathrm{a}^{* *}}\end{array}$ & $\begin{array}{l}1.50(1.00-1.62)^{*} \\
2.50(2.00-3.37)^{a, b^{*}}\end{array}$ & $\begin{array}{l}1.50(1.00-1.62)^{*} \\
2.50(2.00-3.37)^{\mathrm{a}, \mathrm{b}^{*}}\end{array}$ & $\begin{array}{l}1.50(1.00-1.62)^{*} \\
2.50(2.00-3.37)^{\mathrm{a}, \mathrm{b}^{*}}\end{array}$ \\
\hline $\begin{array}{l}\text { Gingival } \\
\text { thickness }\end{array}$ & $\begin{array}{l}\text { MCAT } \\
\text { CCAF }\end{array}$ & $\begin{array}{l}1.00(0.50-1.50)^{\mathrm{b}} \\
1.00(0.62-1.75)^{\mathrm{b}}\end{array}$ & $\begin{array}{l}1.55(1.17-1.87)^{\mathrm{a}} \\
2.50(1.47-3.22)^{\mathrm{a}}\end{array}$ & $\begin{array}{l}1.20(0.80-1.65)^{a, b} \\
2.10(1.15-2.90)^{a, b}\end{array}$ & $\begin{array}{l}1.15(0.60-1.52)^{a, b} \\
2.00(1.12-2.87)^{a, b}\end{array}$ & $\begin{array}{l}1.15(0.60-1.52)^{\mathrm{a}, \mathrm{b}} \\
2.00(1.12-2.87)^{\mathrm{a}, \mathrm{b}}\end{array}$ \\
\hline
\end{tabular}

MCAT: Modified Coronally Advanced Tunnel; CCAF: Conventional Coronally Advanced Flap; a, b: Different letters represent statistically significant differences

between each follow-up period ( $p<0.05$ - Freidman and Dunn Test); ${ }^{*} p<0.05$; ${ }^{* *} p<0.01$ - Intergroup statistically significant differences- Mann- Whitney Test. 


\section{CLINICAL RELEVANCE}

Clinical studies have demonstrated that the use of the connective tissue graft (CTG) ensure superior clinical results in comparison to the platelet-rich fibrin (PRF) and collagen matrix (CM) alone in the gingival recessions treatment. Based on that, the present case series proposed the use of PRF as a combination material, based on its potential to enhance fibroblast activity and angiogenesis stimulation, to improve the $\mathrm{CM}$ clinical results in the treatment of gingival recessions.

\section{CONFLICT OF INTEREST AND FUNDING SOURCE}

No conflict of interest

\section{References}

1. Cairo F, Pagliaro U, Buti J, Baccini M, Graziani F, Tonelli P, et al. Root coverage procedures improve patient aesthetics. A systematic review and Bayesian network meta-analysis. J Clin Periodontol. 2016;43(11):965-75.

2. Huang JP, Liu JM, Wu YM, Chen LL, Ding PH. Efficacy of xenogeneic collagen matrix in the treatment of gingival recessions: A systematic review and metaanalysis. Oral Dis. 2019. 25(4):996-1008.

3. Goldstein M, Boyan BD, Cochran DL, Schwartz Z. Human histology of new attachment after root coverage using a subepithelial connective tissue graft. J Clin Periodontol. 2001:28(7):657-62.

4. Kuka S, Ipci SD, Cakar G, Yilmaz S. Clinical evaluation of coronally advanced flap with or without platelet-rich fibrin for the treatment of multiple gingival recessions. Clin Oral Investig. 2018;22(3):1551-8.

5. Ramireddy S, Mahendra J, Rajaram V, Ari G, Kanakamedala AK, Krishnakumar $D$. Treatment of gingival recession by coronally advanced flap in conjunction with platelet-rich fibrin or resin-modified glass-ionomer restoration: A clinical study. J Indian Soc Periodontol. 2018;22(1):45-9.

6. Lischer BE. The diagnosis of malocclusion. Dent Cosmos 1911:53:412-22.

7. Choukroun J, Diss A, Simonpieri A, Girard MO, Schoeffler C, Dohan SL, et al. Platelet-rich fibrin (PRF): a second-generation platelet concentrate. Part V: histologic evaluations of PRF effects on bone allograft maturation in sinus lift. Oral Surg Oral Med Oral Pathol Oral Radiol Endod. 2006;101(3):299-303.

8. McGuire MK, Scheyer ET. Long-term results comparing xenogeneic collagen matrix and autogenous connective tissue grafts with coronally advanced flaps for treatment of dehiscence-type recession defects. J Periodontol. 2016;87(3):221-7.
9. Kumar RV, Shubhashini N. Platelet rich fibrin: a new paradigm in periodontal regeneration. Cell Tissue Bank. 2013;14(3):453-63.

10. Kumar A, Bains VK, Jhingran R, Srivastava R, Madan R, Rizvi I. Patient-centered Microsurgical management of gingival recession using coronally advanced flap with either platelet-rich fibrin or connective tissue graft: a comparative analysis. Contemp Clin Dent. 2017:8(2):293-304

11. Stefanini M, Jepsen K, de Sanctis M, Baldini N, Greven B, Heinz B, et al. Patient-reported outcomes and aesthetic evaluation of root coverage procedures: a 12-month follow-up of a randomized controlled clinical trial. J Clin Periodontol. 2016:43(12):1132-41.

12. Moreira ARO, Santamaria MP, Silverio KG, Casati MZ, Nociti Junior FH, Sculean A, et al. Coronally advanced flap with or without porcine collagen matrix for root coverage: a randomized clinical trial. Clin Oral Investig. 2016;20(9):2539-49.

13. Cardaropoli D, Tamagnone L, Roffredo A, Gaveglio L. Treatment of gingival recession defects using coronally advanced flap with a porcine collagen matrix compared to coronally advanced flap with connective tissue graft: a randomized controlled clinical trial. J Periodontol. 2012;83(3):321-8.

14. Dohan Ehrenfest DM, de Peppo GM, Doglioli P, Sammartino G. Slow release of growth factors and thrombospondin-1 in Choukroun's platelet-rich fibrin (PRF): a gold standard to achieve for all surgical platelet concentrates technologies. Growth Factors. 2009;27(1):63-9.

15. Tozum TF, Dini FM. Treatment of adjacent gingival recessions with subepithelial connective tissue grafts and the modified tunnel technique. Quintessence Int. 2003;34(1):7-13 